\title{
Egr3/Pilot, a Zinc Finger Transcription Factor, is Rapidly Regulated by Activity in Brain Neurons and Colocalizes with Egr1/zif268
}

Kanato Yamagata, ${ }^{1,6}$ Walter E. Kaufmann, ${ }^{2,6}$ Anthony Lanahan, ${ }^{1}$ Maria Papapavlou, ${ }^{1}$ Carol A. Barnes, ${ }^{3,4,5}$ Katrin I. Andreasson, ${ }^{2}$ and Paul F. Worley ${ }^{1,2,7}$

Departments of ${ }^{1}$ Neuroscience and ${ }^{2}$ Neurology

Johns Hopkins University, School of Medicine

Baltimore, Maryland 21205

Departments of ${ }^{3}$ Psychology, ${ }^{4}$ Neurology, and ${ }^{5}$ Division of Neuronal Systems, Memory and Aging

The University of Arizona

Tuscon, Arizona 84724

\section{Abstract}

Programs of gene activation may underlie long-term adaptive cellular responses to extracellular ligands. We have used a differential cDNA cloning strategy to identify genes that are strongly induced by excitatory stimuli in the adult rat hippocampus. Here, we report the rat cDNA sequence of a zinc-finger transcription factor, Egr3/Pilot, and characterize its regulated mRNA expression in brain. Egr3 mRNA is rapidly and transiently induced in neurons of the hippocampus and cortex by electroconvulsive seizure. mRNA levels peak $2 \mathrm{hr}$ after the seizure and remain elevated for as long as $8 \mathrm{hr}$. Egr $3 \mathrm{mRNA}$ is also rapidly induced in granule cells of the dentate gyrus by synaptic NMDA receptor activation elicited by patterned stimulation of the perforant pathway and by drugs that alter dopamine neurotransmission in the striatum. Basal levels of Egr3 mRNA in the cortex appear to be driven by natural synaptic activity because monocular deprivation rapidly decreases Egr 3 mRNA in the deafferented visual cortex. Aspects of the protein structure, sequence-specific

\footnotetext{
${ }^{6}$ Both authors contributed equally to this work.
} ${ }^{7}$ Corresponding author.
DNA binding, transcriptional activity, and regulation of Egr 3 are highly similar to another zinc-finger transcription factor, Egr1/zif268. Moreover, we demonstrate colocalization of Egr3 and zif268 mRNAs in neurons of normal and stimulated cortex. Our studies suggest that interactions between these coregulated transcription factors may be important in defining long-term, neuroplastic responses.

\section{Introduction}

Neurons exhibit the capacity to alter functional and anatomic properties in response to transmitters and growth factors. This capacity of neurons is believed to be essential for learning and memory and is prominently manifest during postnatal development of the neocortex where ocular dominance column formation is dependent on glutamatergic synaptic activity (for review, see Shatz 1990). Kandel and co-workers have demonstrated that long-term changes in synaptic connectivity and structure, that occur in response to transmitter stimulation, require new mRNA and protein synthesis during a relatively brief time window following the stimulus (Montarolo et al. 1986; Bailey et al. 1992). Insight into the cellular mechanisms underlying long-term plasticity has come from studies of growth factor signaling that indicate that receptor activation is linked to the rapid

LEARNING \& MEMORY 1:140-152 (c) 1994 by Cold Spring Harbor Laboratory Press ISSN1072-0502/94 \$5.00

$$
\begin{array}{lllllllllllllll}
L & E & A & R & N & I & N & G & \underset{140}{\bigotimes} & M & E & M & O & R & Y
\end{array}
$$


induction of regulatory genes, termed immediateearly genes (IEG) (for review, see Nathans et al. 1991). Several lines of evidence support the concept that coordinate and sequential gene regulation may also be relevant to understanding activity-dependent neuronal plasticity (Sheng and Greenberg 1990).

Studies using cultured invertebrate neurons demonstrate that interruption of a specific, IEG transcription factor blocks transmitter induced long-term synaptic plasticity (Alberini et al. 1994). In vertebrate systems, evidence linking IEGs with plasticity remains correlative but is compelling because of the close association between gene expression and the conditions that result in longterm plastic changes. The zinc-finger transcription factor termed zif268 [(Christy et al. 1988). also termed Egrl (Sukhatme et al. 1988), NGFI-A (Milbrandt 1987), Krox24 (Lemaire et al. 1988), and T1S8 ( Lim et al. 1987)] is a notable example of an IEG that is dynamically regulated in mammalian and avian brain in association with stimuli that induce long-term plastic changes. zif 268 is rapidly and transiently induced in neurons of the hippocampus by synaptic NMDA receptor-dependent stimuli in association with long-term potentiation (Cole et al. 1989; Worley et al. 1993 and refs. therein ). zif 268 is also rapidly induced in the forebrain of songbirds upon presentation and learning of their species specific song (Mello et al. 1992). zif 268 is developmentally regulated, and peak expression in rodent and cat cortex occurs during the postnatal period when cortical architecture is maximally sensitive to environmental stimuli (Worley et al. 1990; McCormack et al. 1992). zif268 is expressed at high basal levels in neurons of the cerebral cortex, and this expression is regulated by natural synaptic activity, which is known to be important for maintaining the phenotype of neurons in the adult cortex (Worley et al. 1991; Chaudhuri and Cynader 1993). These observations suggest that transcription factors, such as zif268, play a role in activity-dependent neuronal plasticity in the developing and adult vertebrate brain.

To further define the gene program induced in neurons of the mammalian brain by synaptic activity, we and others have used differential cDNA cloning techniques to identify mRNAs rapidly induced in the rodent hippocampus by excitatory stimuli (Nedivi et al. 1993; Qian et al. 1993; Yamagata et al. 1993). In our studies, one of the most abundant differential cDNAs (based on the frequency of isolates) encodes the rat homolog of the transcription factor Egr3. Egr3 is a $43-\mathrm{kD}$ nuclear phosphoprotein with a zinc finger motif that is highly homologous to the zinc fingers of zif268/ Egr 1 (Patwardhan et al. 1991). Egr3 binds the DNA sequence 5'-GCGGGGGCG-3' and activates transcription (Patwardhan et al. 1991). This DNA sequence is identical to the consensus sequence recognized by zif268 (Christy and Nathans 1989; Cao et al. 1990). Despite these similarities, zif268 and Egr3 also exhibit several important differences. Outside of the zinc-finger domains, zif 268 and Egr 3 are only $\sim 30 \%$ identical, suggesting that they may have distinct regulatory functions. zif268 is widely expressed in adult tissues (Sukhatme et al. 1987, 1988; Christy et al. 1988) and, as noted, is induced by a variety of stimuli in brain. In contrast, initial studies of Egr3 could not detect its mRNA expression in adult tissues (Patwardhan et al. 1991).

Because $E g r 3$ is abundantly represented in our differential cDNA analysis of stimulated brain and because of its many similarities to $z i f 268$, we undertook a more detailed analysis of its expression and regulation. Here, we report the sequence of the rat homolog of Egr 3 and characterize its mRNA expression and cellular distribution in brain. Our data indicate that Egr3 mRNA is expressed at relatively high levels in neurons of normal brain and is rapidly regulated in parallel with zif268. Moreover, zif268 and Egr3 mRNAs have similar developmental and anatomic patterns of expression and are coexpressed in discrete populations of neurons of the normal and stimulated cortex. Because zif268 and Egr3 bind to the same consensus DNA sequence, our observations suggest that interactions between these transcription factors may be important in defining specific transcriptional responses in brain neurons.

\section{Materials and Methods}

\section{CONSTRUCTION AND SCREENING OF THE SUBTRACTED CDNA LIBRARY}

A subtracted cDNA library was constructed as described (Yamagata et al. 1993). The subtracted library was screened with ${ }^{32}$ P-labeled cDNA prepared by reverse transcription of poly $(\mathrm{A})^{+}$RNA prepared from hippocampus of control or seizure stimulated rats pretreated with cycloheximide ( 20 $\mathrm{mg} / \mathrm{kg}$, i.p.) as described previously (Lanahan et al.

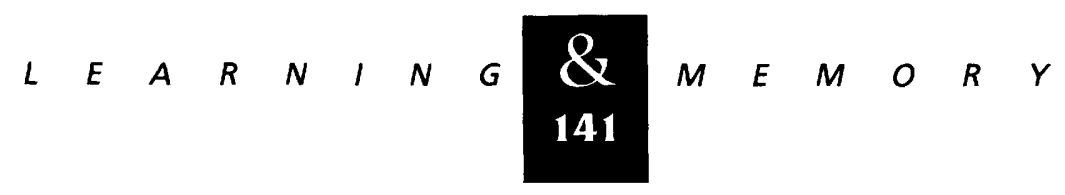


1992; Yamagata et al. 1993). cDNA clones of the rat homolog of $E g r 3$ represented $\sim 30 \%$ of all differential cDNA isolates ( 14 of 47). A near full length cDNA of rat Egr3 was isolated by iterative screening of an unsubtracted, oligo(dT)-primed cDNA library prepared from hippocampus $4 \mathrm{hr}$ postseizure.

\section{DNA SEQUENCING}

Both strands of $E g r 3$ cDNA corresponding to the open reading frame were sequenced as double-stranded plasmids with synthetic, specific primers by the dideoxynucleotide chain termination method using deoxyadenosine $5^{\prime}-\left[\alpha-{ }^{35} S\right]$ thio triphosphate and Sequenase (U.S. Biochemical).

\section{NORTHERN BLOT ANALYSIS}

This procedure was performed as described (Linzer and Nathans 1983) with $10 \mu \mathrm{g}$ of total RNA per lane. The probe used for Northern analysis was a 1.7-kb 3' end fragment of rat Egr3 cDNA that is entirely a noncoding sequence and is not homologous to other zinc finger genes. The cDNA fragment was labeled by the random priming technique (Pharmacia) using $\left[\alpha-{ }^{32} \mathrm{P}\right] \mathrm{dCTP}$.

\section{IN SITU HYBRIDIZATION}

Freshly dissected brain tissue was frozen rapidly in plastic molds placed on a dry-ice/ethanol slurry as described previously (Cole et al. 1990). Control and experimental tissues were frozen in the same tissue block to assure identical conditions during tissue sectioning, subsequent storage, and in situ hybridization. ${ }^{35}$ S-Labeled Egr3 antisense riboprobe was prepared from an appropriately restricted pBS plasmid containing a $1.7-\mathrm{kb}$ Egr3 3' cDNA sequence that, as noted above, is unique for Egr3. Digoxigenin-labeled zif268 antisense cRNA was prepared from a full-length cDNA cloned in pBS according to the manufacturer's protocol (Boehringer Mannheim). In situ hybridization was performed as described (Saffen et al. 1988). The concentration of riboprobes was $20-40 \times 10^{6} \mathrm{cpm} / \mathrm{ml}$ of hybridization buffer $(50 \%$ formamide, $600 \mathrm{~mm} \mathrm{NaCl}, 1 \times$ Denhardt's solution, $10 \mathrm{~mm}$ Tris-Cl at $\mathrm{pH} 7.4,1 \mathrm{~mm}$ EDTA, $0.2 \mathrm{mg} / \mathrm{ml}$ of yeast tRNA, $10 \mathrm{~mm}$ DTT, $10 \%$ dextran sulfate, 100 $\mu \mathrm{g} / \mathrm{ml}$ heat-denatured, sheared salmon sperm
DNA) for $E g r 3$ and $\sim 1 \mu \mathrm{g} / \mathrm{ml}$ for $z i f 268$. Tissue sections were incubated under glass coverslips overnight at $56^{\circ} \mathrm{C}$. Coverslips were removed in $2 \times$ SSC ( $10 \mathrm{~min}$ at room temperature), and tissue sections were washed in $2 \times \mathrm{SSC}(2 \times 10 \mathrm{~min}$ at room temperature) followed by incubation in $2 \times$ SSC containing $10 \mathrm{~mm} \beta$-mercaptoethanol and $10 \mu \mathrm{g} /$ $\mathrm{ml}$ of RNase A (Worthington) for $30 \mathrm{~min}$ at $37^{\circ} \mathrm{C}$ and subsequently washed $20 \mathrm{~min}$ in $2 \times \mathrm{SSC}$. For experiments examining Egr3 mRNA alone, tissue sections were briefly dipped in $\mathrm{dH}_{2} \mathrm{O}$, dehydrated through ascending ethanols, and exposed to XAR5 film for 12-72 hr. For studies of combined localizations of Egr3 and zif268, the digoxigenin-labeled riboprobe was first detected using an alkaline phosphatase-linked, antidigoxigenin antiserum (Boehringer Mannheim) according to the manufacturer's directions. Typically, the alkaline phosphatase reaction was continued for $\sim 18 \mathrm{hr}$. Tissue sections were then dehydrated and dipped in a $2 \%$ collodion solution (Electron Microscopy Sciences) to prevent reactivity between the alkaline phosphatase product and the photographic emulsion (Young 1989). Selected slides were treated with photographic emulsion (Kodak NTB2) and counterstained as described previously (Jordan 1990). Operationally, positive alkaline phosphatase reaction was defined as staining sufficiently strongly to clearly delineate cellular borders. In addition, staining in the relatively hypocellular molecular layer served as an internal background control for layers II-VI. The validity of our double-labeling analysis was confirmed by simultaneous trials in adjacent sections, using radiolabeled probes for both genes, which displayed similar relative proportions of mRNA labeling.

\section{ELECTROPHYSIOLOGY}

Maximal electroconvulsive seizures (MECS) were induced in adult rats using a constant current signal generator (ECT unit, Ugo Basil) as described previously (Cole et al. 1990). For long-term potentiation (LTP) studies, Fischer-344 rats were implanted bilaterally with stimulating and recording electrodes in the perforant path and hilus of the dentate gyrus as described previously (Worley et al. 1993). Rats were allowed to recover for at least 3 weeks before any recordings were performed.

To examine the regulation of Egr3 mRNA by synaptic stimuli, 12 chronically implanted rats received high-frequency (HF) stimulation in one

$$
\text { n...n. }
$$


hemisphere and low-frequency (LF) stimulation in the other hemisphere. Electrical stimuli consisted of $200 \mathrm{msec}$ diphasic, constant current pulses given at a stimulus intensity of $500 \mathrm{~mA}$. The LF test stimulation was delivered at $0.1 \mathrm{~Hz}$, and the $\mathrm{HF}$ stimulation parameters consisted of 50 repetitions of a 20 -msec train (i.e., 8 pulses) delivered at 400 $\mathrm{Hz}$ (400 total pulses). The HF parameters reliably induce LTP (Dragunow et al. 1989; Jeffrey et al. 1990; Abraham et al. 1992; Worley et al. 1993). Following this treatment, the rats were sacrificed at either $30 \mathrm{~min}(n=6), 1 \mathrm{hr}(n=2), 2 \mathrm{hr}(n=2)$, or $4 \mathrm{hr}(n=2)$. Three additional animals were pretreated with MK-801 ( $1 \mathrm{mg} / \mathrm{kg}$, i.p.) $1 \mathrm{hr}$ prior to the delivery of the HF stimulus. The intensity of the stimulus was adjusted such that the postsynaptic population response was identical to that prior to MK-801 administration. Animals were sacrificed $30 \mathrm{~min}$ after the $\mathrm{HF}$ stimulus and processed for in situ hybridization.

\section{VISUAL DEAFFERENTATION AND ADMINISTRATION OF DOPAMINERGIC AGENTS}

Visual deafferentation was performed in adult Sprague-Dawley rats as described previously (Worley et al. 1991) using monocular, intravitreal injections of the sodium channel antagonist tetrodotoxin (TTX). Dopaminergic agents were admin- istered by intraperitoneal injection as described previously (Cole et al. 1992) and included cocaine ( $15 \mathrm{mg} / \mathrm{kg}$ ), the selective $D_{1}$ receptor antagonist SCH 23390 (Hyttel 1983; $0.5 \mathrm{mg} / \mathrm{kg}$ ), and the $\mathrm{D}_{2}$ receptor antagonist haloperidol $(1 \mathrm{mg} / \mathrm{kg})$.

\section{Results}

\section{NUCLEOTIDE AND AMINO ACID SEQUENCE OF Egr3}

We cloned and sequenced a nearly full-length cDNA of rat Egr3/Pilot cDNA. This cDNA encodes a single open reading frame of 387 amino acids and a calculated molecular weight of 42,579 . Its amino acid sequence is $98 \%$ identical to human Egr3/Pilot (Patwardhan et al. 1991; Mages et al. 1993). Figure 1 shows a comparison of amino acid sequences of rat Egr3, human Egr3 (Patwardhan et al. 1991), and rat NGFI-A. Figure 2 is a schematic representation of the zinc-finger domains of rat Egr3 and NGFI-A (identical to zif268) underscoring their high homology.

\section{EXPRESSION OF Egr3 IN BRAIN NEURONS AND INDUCTION BY SEIZURE}

Egr3 mRNA was detected in control hippocampus, using Northern blots of total RNA, and

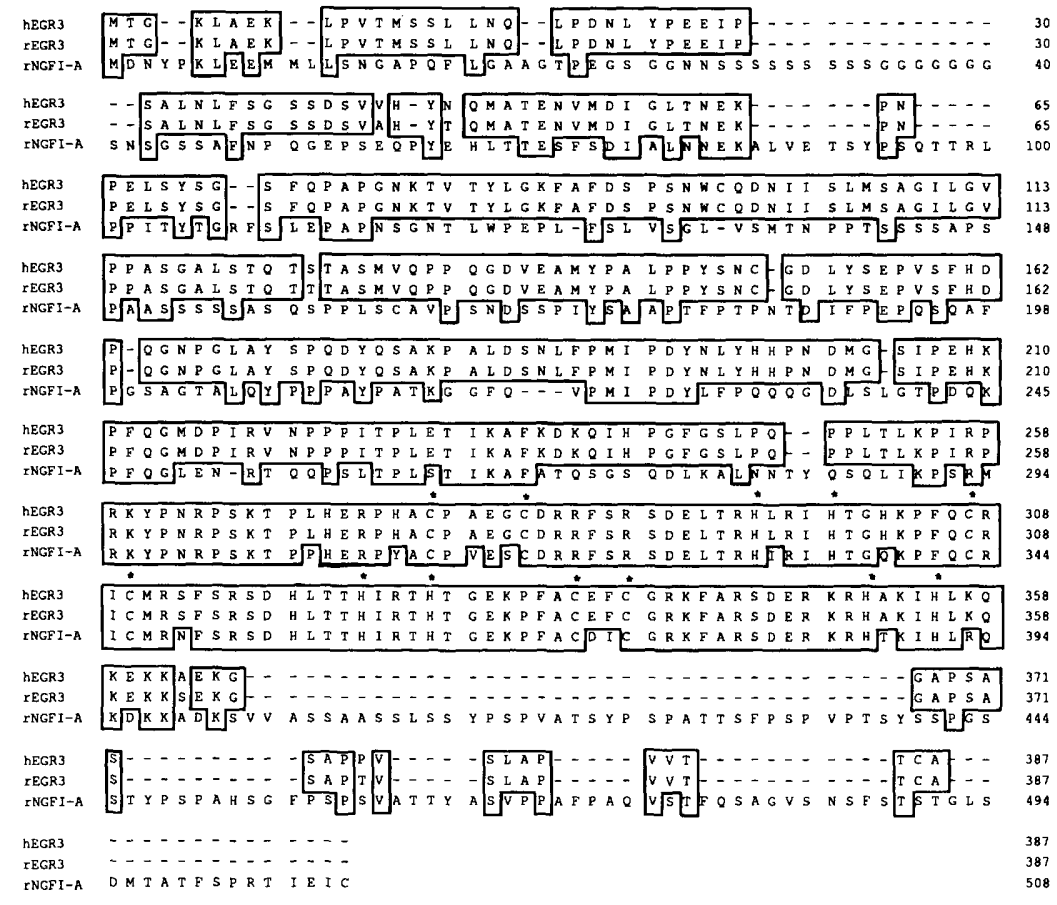

Figure 1: Comparison of the predicted rat (r) Egr3 protein, human (h) Egr3 protein (Patwardhan et al. 1991), and rat (r) NGFI-A (Milbrandt 1987). The conserved cysteine and histidine residues of the zinc fingers are marked with an asterisk $\left.{ }^{*}\right)$. The amino acids that are conserved in two or more members are boxed. The nucleotide sequence has been entered into GenBank under accession number U12428.

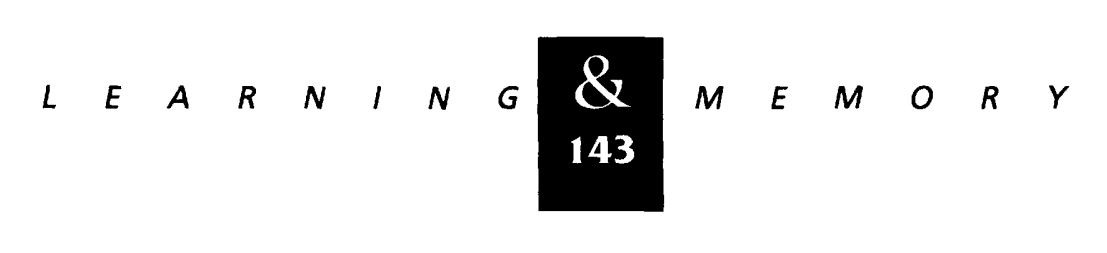




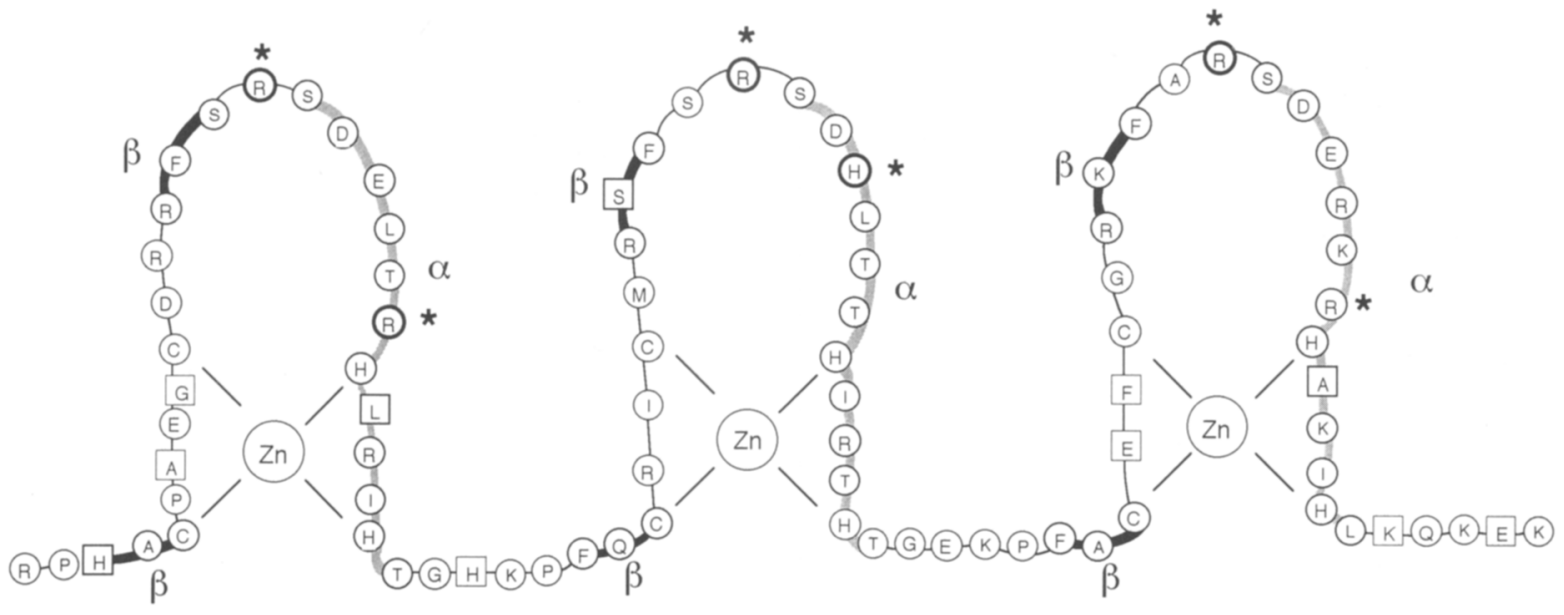

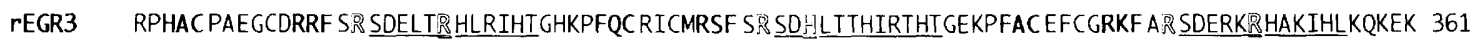

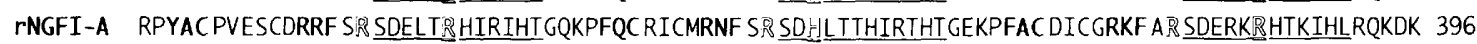

Figure 2: Diagrammatic representation of the three rat $(r) \mathrm{rEgr} 3$ zinc fingers predicted from the crystal structure of NGFI-A (Pavletich and Pabo 1991). Amino acid loops or fingers are produced by cysteine and histidine pairs that chelate a zinc ion. Each zinc finger contains two $\beta$-sheets (thick black lines) and one $\alpha$-helix domain (thick gray line). Two residues in each zinc finger (star) contact guanine nucleotides in the major groove of the DNA. rEgr3 and rNGFI-A conserved residues are encircled, whereas nonconserved are contained in squares (rNGFI-A and zif268 zinc-finger domain sequences are identical). Below the diagram, rEgr3 and rNGFI-A zinc-finger sequences are compared. $\beta$-Sheet residues are in bold, $\alpha$-helix domains appear underlined, and DNA contacts are outlined.

was strongly induced by a single MECS (Fig. 3A). The message is $\sim 4.4 \mathrm{~kb}$ and is very similar in size to the human transcript (Patwardhan et al. 1991; Mages et al. 1993). In situ hybridization was performed to examine the time course and anatomi- cal distribution of basal and induced $E g r 3$ mRNA in hippocampus. Egr $3 \mathrm{mRNA}$ was strongly induced in granule cells within $30 \mathrm{~min}$ after MECS, peaked within 1-2 hr, and remained elevated as long as 8 hr after the seizure (Fig. 3B). The time course of
Figure 3: Regulation of Egr3 mRNA expression by seizure. (A) Northern analysis. Total RNA was prepared from hippocampus of control rats and rats pretreated for $30 \mathrm{~min}$ with cycloheximide (20 $\mathrm{mg} / \mathrm{kg}$ ) and sacrificed $4 \mathrm{hr}$ after MECS. Ten micrograms was loaded per lane. Arrows indicate the positions of the $18 \mathrm{~S}$ and $28 \mathrm{~S}$ ribosomal bands. (B,C) Time course of $\operatorname{Egr} 3(B)$ and zif268 (C) mRNAs in hippocampus after seizure. Hippocampi were dissected from control rats and from rats $0.5,1,2,4,6,8$, and $24 \mathrm{hr}$ after MECS and $6 \mathrm{hr}$ after MECS from an animal pretreated with cycloheximide. The hippocampi from the different time points were processed for in situ hybridization together in a single tissue block to assure identical hybridization conditions. Magnification, $\sim 4 \times$. The time of sacrifice after MECS is indicated by the number above each individual hippocampus. MECS induces an increase in Egr3 (B) and zif268 (C) mRNAs in the granule cell layer of the hippocampus, which is indicated by the arrowhead in the control (c) hippocampus. Note that Egr3 mRNA remains elevated at $8 \mathrm{hr}$ whereas zif 268 mRNA returns to basal levels by $6 \mathrm{hr}\left({ }^{*}\right)$.

$$
\text { …..... }
$$


the increase in Egr3 mRNA following MECS was somewhat prolonged compared with that of zif268, which returned to basal levels by $6 \mathrm{hr}$. Both Egr3 and zif268 mRNAs were strongly induced in animals pretreated with cycloheximide, suggesting that they are regulated as IEG in brain (Qian et al. 1993).

Egr3 and zif268 mRNA localizations in forebrain were examined and compared in control and MECS stimulated rats. In control rat brain, highest levels of Egr3 mRNA were detected in cerebral cortex, caudate-putamen, amygdala and hippocampal granule, and pyramidal cell layers (Fig. 4A). Two hours after a single MECS, Egr3 mRNA increased dramatically in the hippocampus, superficial and deep layers of the cerebral cortex, piriform cortex, amygdala, and hypothalamus. The an-
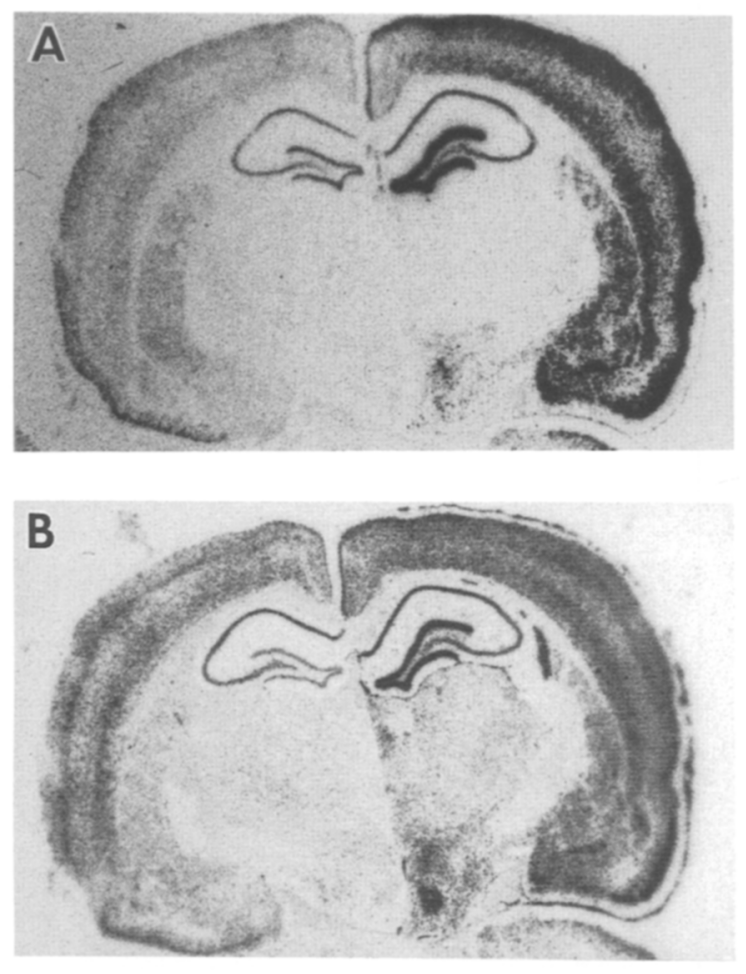

Figure 4: Comparison of anatomic localizations of Egr3 and zif268 mRNAs in forebrain assayed by in situ hybridization. Composite figure showing coronal sections of unstimulated (left half-brain) and MECS-stimulated (right half-brain) rat brain. Egr3 $(A)$ and zif268 (B) basal mRNA levels are detected in cerebral cortex, hippocampus, basal ganglia, and amygdaloid complex. After MECS, there is a marked increase in both mRNAs in these same regions. Note the overall similarity in the pattern of basal and induced expression of Egr3 and zif268. Magnification, $\sim 5 \times$. atomic pattern of Egr3 mRNA is very similar to that of $z i f 268$ in both the control and MECS stimulated forebrain (Fig. 4B).

Photographic emulsion was used to determine the cellular localization of $E g r 3$ mRNA by in situ hybridization. In control and MECS stimulated forebrain, clusters of autoradiographic grains were associated with neurons based on the size, cytological features, and staining properties of the cells. In control brain, double in situ localizations of Egr3 and zif268 (detected using digoxigeninlabeled riboprobe) demonstrated, in addition to well-defined digoxigenin-labeled profiles and independent clusters of grains, double-labeled cells that represented coexpression of these mRNAs in a subset of neurons in layer 2-3 of the neocortex (Fig. 5A). Coexpression of Egr3 and zif 268 mRNAs was also detected in subsets of neurons in layers 5-6 of neocortex, layer 2 of piriform cortex, and pyramidal cells of hippocampus in control animals (not shown). Although we did not quantitate the number of neurons coexpressing Egr3 and zif268 relative to the numbers expressing either mRNA alone, cells expressing both mRNAs were abundant in all microscopic fields. Two hours after MECS, there was a large increase in the number of neurons expressing either Egr3 or zif268 (increase in cell number and intensity of cell staining) and many cells coexpressed the mRNAs (Fig. $5 B)$.

\section{STIMULATION OF Egr3 mRNA BY NMDA RECEPTOR ACTIVATION}

The chronic in vivo LTP paradigm was used to deliver monosynaptic stimuli of defined intensities and frequencies to granule cells of the hippocampus in alert, behaving rats (McNaughton et al. 1986; Worley et al. 1993). Egr3 mRNA was strongly induced in the hippocampal granule cells ipsilateral to the HF stimuli (Fig. 6) in each of six animals sacrificed $30 \mathrm{~min}$ after the stimulus, as well as in each of the animals sacrificed after $1 \mathbf{~ h r}$ $(n=2), 2 \mathrm{hr}(n=2)$, or $4 \mathrm{hr}(n=2)$. No induction was detected in granule cells that received the LF stimulation $(n=12)$ or in hippocampus that had been implanted with electrodes but not electrically stimulated $(n=2)$.

Consistent with previous studies (McNaughton et al. 1986; Worley et al. 1993), this pattern of HF stimulation induced LTP in each of these animals. LTP induced by HF stimulation is dependent

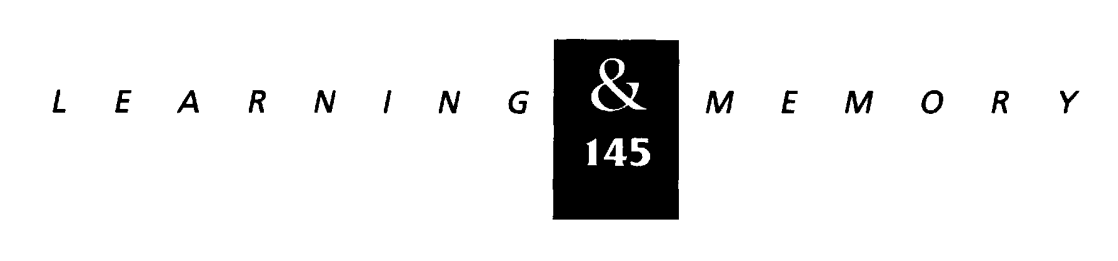


Figure 5: Localization of zif268 and Egr3 mRNAs in cortex of control $(A)$ and seizure-stimulated $(B)$ rats. zif268 mRNA is detected using digoxigenin-labeled riboprobe (alkaline phosphatase reaction product that fills the cell soma), and Egr3 is detected with ${ }^{35} \mathrm{~S}$-labeled riboprobe (autoradiographic silver grains) as described in Materials and Methods. Photomicrographs are from superficial layers of somatosensory cortex. zif268 and Egr3 mRNAs are expressed in neurons of lamina $2-3$ ( $\mathrm{ml}=$ molecular layer). A subpop-

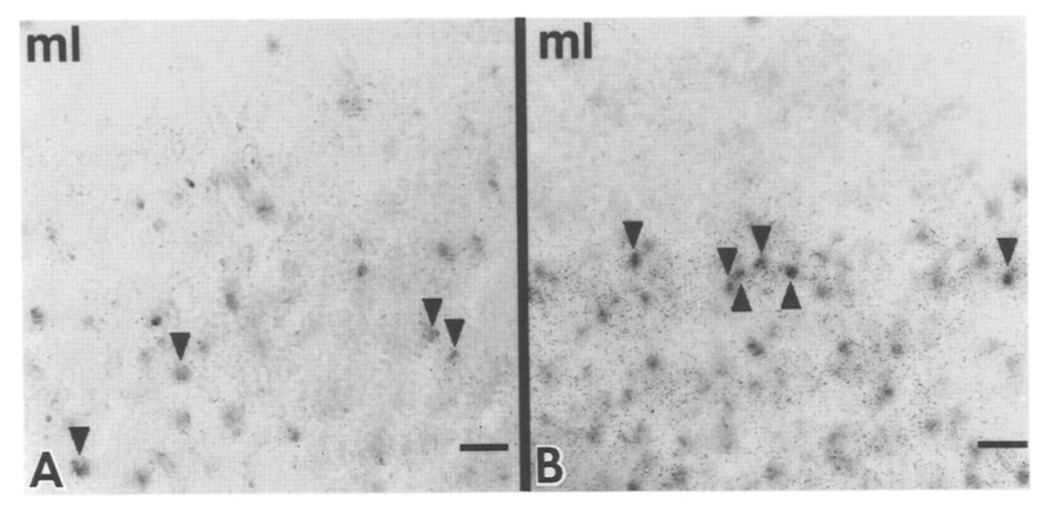
ulation of neurons coexpresses zif268 and Egr3 (arrowheads). One hour after MECS, there is a large increase in the number of neurons expressing either zif268 or Egr3 and both mRNAs. Bar, $100 \mu \mathrm{m}$.

on activation of NMDA-type glutamate receptors (Abraham and Mason 1988). To examine whether the induction of $E g r 3$ mRNA is mediated by NMDA receptor activation, we pretreated rats with the noncompetitive NMDA receptor antagonist MK$801(1 \mathrm{mg} / \mathrm{kg}) 1 \mathrm{hr}$ prior to delivery of the standard HF stimulus and sacrificed animals $30 \mathrm{~min}$ after the stimulus. In animals pretreated with MK$801(n=3)$, there was no detectable induction of

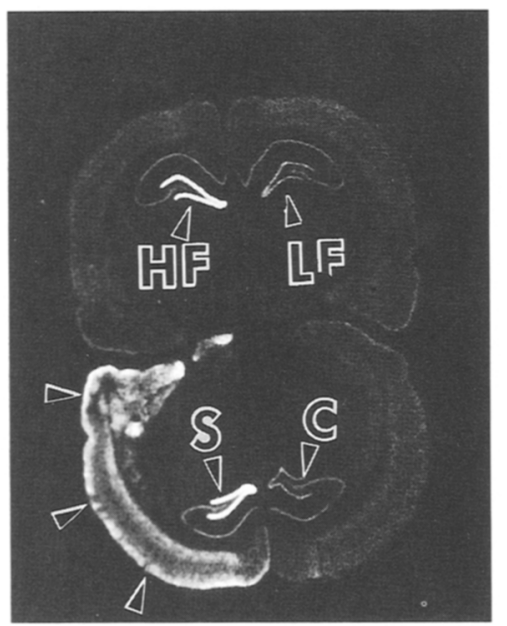

Figure 6: Induction of Egr3 mRNA in hippocampal granule cells by HF stimulation of the perforant pathway. Rats were chronically implanted for in vivo recording and were stimulated as described in Materials and Methods. Stimulated brains were analyzed by in situ hybridization together with half-brains from naive control (C) and MECS-stimulated (S) rats. Egr3 mRNA is increased in the granule cell layer of the hippocampus 30 min after the HF but not the LF stimulus. Note that the magnitude of Egr3 mRNA induction by the HF stimulus is comparable with that of MECS. Identical results were obtained in each of five additional animals killed $30 \mathrm{~min}$ after onset of HF stimulation.
Egr3 mRNA in the hippocampus by the HF stimulus (not shown).

\section{ACTIVATION OF Egr3 mRNA BY COCAINE AND HALOPERIDOL}

To determine whether dopaminergic stimulation can activate Egr 3 mRNA in adult rat brain, we examined the effect of cocaine administration on Egr3 mRNA levels using in situ hybridization. Cocaine $(15 \mathrm{mg} / \mathrm{kg})$ produced a rapid increase in Egr3 mRNA levels in the striatum (Fig. 7A). Egr3 mRNA was induced within $1 \mathrm{hr}$ and remained elevated $4 \mathrm{hr}$ after cocaine administration. Induction of Egr 3 by cocaine was blocked by prior treatment with the selective $D_{1}$ receptor antagonist $\mathrm{SCH}$
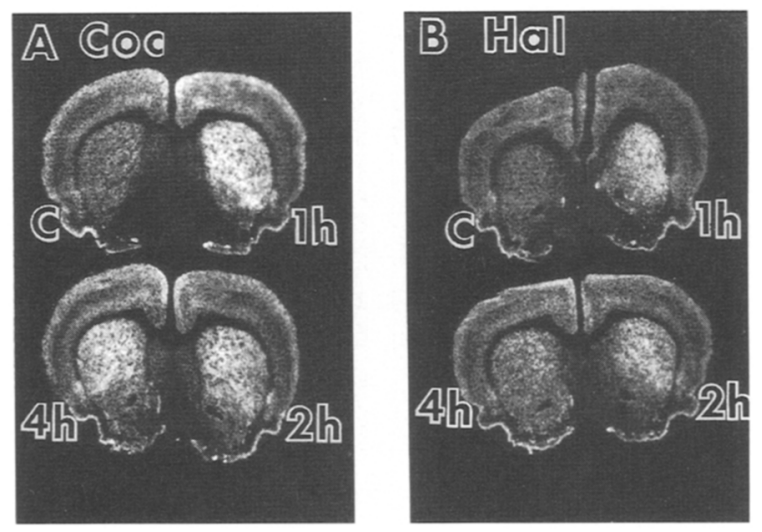

Figure 7: $\operatorname{Egr} 3 \mathrm{mRNA}$ is rapidly induced in the striatum following acute administration of cocaine $(15 \mathrm{mg} / \mathrm{kg})$ or haloperidol (1 mg/kg). Half-brains from control rats (C) and rats sacrificed at the indicated times (1, 2, and $4 \mathrm{hr}$ ) after drug administration were processed together for in situ hybridization. Magnification, $\sim 4 \times$. Note that cocaine and haloperidol induce Egr 3 mRNA selectively in the striatum and persist to $4 \mathrm{hr}$.

$$
\text { n..... }
$$


$23390(0.5 \mathrm{mg} / \mathrm{kg}$ administered $30 \mathrm{~min}$ before cocaine; data not shown). In contrast, administration of the $D_{2}$ antagonist haloperidol $(1 \mathrm{mg} / \mathrm{kg})$ resulted in a rapid increase in Egr3 mRNA in the striatum (Fig. 7B). These responses of Egr3 mRNA are similar to those of $z i f 268$ reported previously (Cole et al. 1992; Nguyen et al. 1992).

\section{REGULATION OF BASAL EXPRESSION BY NATURAL SYNAPTIC ACTIVITY}

We examined the hypothesis that basal Egr3 expression in the cortex is regulated by natural synaptic activity. Interruption of afferent synaptic activity to the visual cortex, by infusing tetrodotoxin into one eye, results in a rapid and anatomically discrete decrease in zif $268 \mathrm{mRNA}$ in the deprived visual cortex of rats (Worley et al. 1991). Consistent with previous studies, zif268 mRNA was reduced in the primary visual cortex of rats that received an intravitreal injection of tetrodotoxin $18 \mathrm{hr}$ prior to sacrifice (Fig. 8B). Egr3 was similarly reduced in the primary visual cortex of these rats (Fig. 8A, $n=3$ ).

\section{DEVELOPMENTAL REGULATION OF Egr3 mRNA}

In situ analysis of newborn (day 1 ) pups demonstrates Egr3 mRNA is enriched in the caudate-
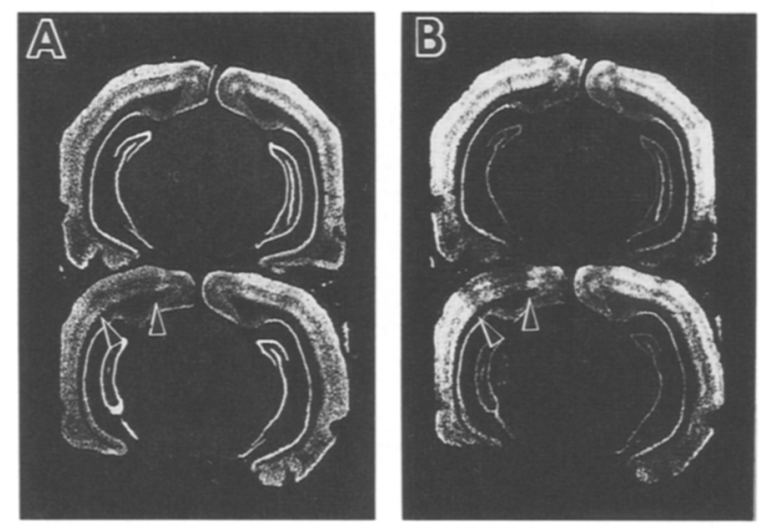

Figure 8: $\quad$ Egr3 and zif268 mRNAs are regulated by afferent visual activity. Adult rats received monocular, intravitreal injections of TTX and were sacrificed $18 \mathrm{hr}$ later. In situ hybridization of $\operatorname{Egr3}(A)$ and zif268 (B) mRNAs is reduced in primary visual cortex contralateral to the ocular TTX injection. Arrowheads at lower left of each photograph indicate the region of reduced hybridization in the visual cortex. Upper panels correspond to control brains hybridized, for each probe, simultaneously to TTX-injected subjects. Magnification, $\sim 4 \times$.
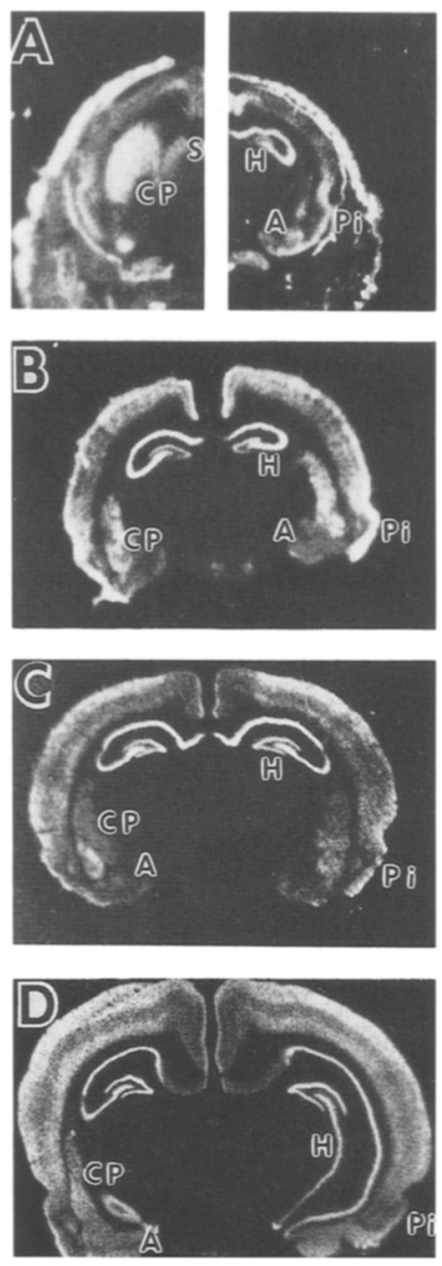

Figure 9: Developmental regulation of Egr3 mRNA in rat brain. In situ localizations at postnatal days $1(A), 5$ $(B), 12(C)$, and $21(D)$. Magnification, $\sim 3 \times$. Egr3 $m R N A$ is prominent in the caudate putamen (CP), septum $(\mathrm{S})$, hippocampus $(\mathrm{H})$, amygdala $(\mathrm{A})$, and piriform cortex $(\mathrm{Pi})$ at day 1 . By day 5 , levels are also prominent in the neocortex. The pattern of expression at day 12 and 21 is similar to the adult.

putamen, septum, piriform cortex, and hippocampal CA1-CA4 regions (Fig. 9A). By postnatal day 5, Egr3 mRNA is also enriched in neocortical regions (Fig. 9B). Day 12 and 21 forebrains demonstrate a qualitatively similar pattern of expression to that of adult brain (Fig. 9C,D).

\section{Discussion}

\section{CLONING OF RAT Egr3}

We are using a differential cloning strategy to identify genes that are rapidly regulated in brain

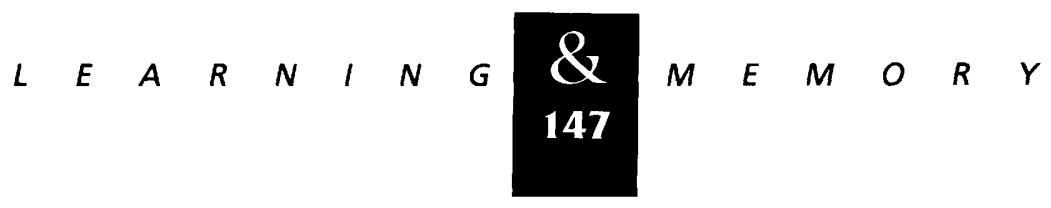


neurons in response to transmitter stimulation as approach to understand the molecular basis of neuronal plasticity (Yamagata et al. 1993). The rat homolog of Egr3 was identified and characterized on the basis of its rapid induction in brain by depolarizing stimuli. The nucleotide and predicted amino acid sequences of rat Egr3 are highly homologous to the human sequences. The predicted rat Egr 3 amino acid sequence is $98 \%$ identical to the human sequence, and all substitutions are conservative.

Aspects of the protein structure and transcriptional activity of Egr 3 are discussed with the initial characterization of this gene (Patwardhan et al. 1991; Mages et al. 1993) and are reviewed here only briefly. Egr 3 contains three tandem zinc finger structures near its carboxyl terminus. Within this region, Egr3 is highly homologous to other members of the family of $\mathrm{Cys}_{2}-\mathrm{His}_{2}$ zinc-finger transcription factors that includes zif268, Egr2 (Chavrier et al. 1988; Joseph et al. 1988), NGFI-C, and the Wilms' tumor gene product (Rauscher et al. 1990). The crystal structure of the zif268-DNA complex indicates that each zinc finger contains a $\beta$-sheet domain in the amino-terminal region of the finger and a $\alpha$-helical domain in the carboxyl half of the finger (Pavletich and Pabo 1991). A zinc ion is chelated by two histidines in the $\alpha$-helical domain and two cysteines in the $\beta$-sheet. Amino acid residues from the amino-terminal portion of the $\alpha$-helix contact base side chains of the G-rich strand in the major groove. Consistent with the high degree of conservation within their finger regions, each of the members of this group of zinc finger transcription factors binds to the same consensus DNA sequence (Christy and Nathans 1989; Cao et al. 1990; Chavrier et al. 1990; Lemaire et al. 1990; Rausher et al. 1990; Crosby et al. 1991; Patwardhan et al. 1991; Mages et al. 1993).

Analysis of the Egr 3 amino acid sequence in the nonfinger domain shows an abundance of proline, serine, and alanine. The homologous regions of zif268, Egr 2, and NGFI-C are also rich in these amino acids, and like these other zinc finger transcription factors, Egr3 demonstrates sequencespecific transcriptional activation (Patwardhan et al. 1991). Proline rich regions have been described as activator domains of transcription factors (Mermod et al. 1989), including zif268 (Gashler et al. 1993), and this general conservation may reflect an underlying common functional role. However, there is only $\sim 30 \%$ identity in this region between zif268 and Egr3, and domains that might confer distinct functions on Egr3 have not yet been identified.

\section{REGULATION OF Egr3 mRNA IN BRAIN}

Initial studies characterizing Egr3 demonstrated its expression in mitogen-stimulated fibroblasts and $\mathrm{T}$ cells but suggested that its expression may be highly restricted in other tissues (Patwardhan et al. 1991; Mages et al. 1993). Our data provide the first demonstration of the expression and regulation of Egr3 in the whole animal. Egr3 mRNA is detected in many neuronal populations in normal brain and is strongly induced in the adult brain by depolarizing stimuli. After a single MECS, Egr3 mRNA increases markedly in hippocampal granule cells, neurons of the piriform cortex, amygdala, and neurons of layers 2-3 and 5-6 of the neocortex. The time course of Egr3 mRNA induction after MECS is rapid and transient and similar to its time course of expression in fibroblasts following serum stimulation (Patwardhan et al. 1991).

zif268, NGFI-C, and Krox20 are also rapidly and transiently induced in hippocampal neurons by MECS (Cole et al. 1990; Bhat et al. 1992; Crosby et al. 1992). A direct comparison of the time courses of Egr3 and zif268 mRNA responses in hippocampal granule cells following MECS indicates that their initial inductions are similarly rapid but that Egr3 mRNA remains elevated several hours longer than zif268. Differences in the time courses of these highly related proteins could be important in effecting specific responses to a particular stimulus. For example, at early time points, Egr 3 and zif268 might compete for the same enhancer regions, whereas at later points, Egr 3 could act alone. Accordingly, it will be important to determine if this difference in time course between zif268 and Egr3 mRNAs is also manifest at the level of the protein.

Egr3 mRNA is induced in hippocampal granule cells by NMDA-dependent synaptic mechanisms. Using the chronic in vivo LTP paradigm, HF, but not LF, stimulation of perforant-pathway afferents results in a robust induction of Egr3 mRNA. The time course of this response appears similar to that induced by MECS. Consistent with previous studies (Abraham and Mason 1988; Reed and Robinson 1991; Worley et al. 1993), systemic administration of an NMDA-type glutamate receptor antagonist blocked synaptic enhancement in our

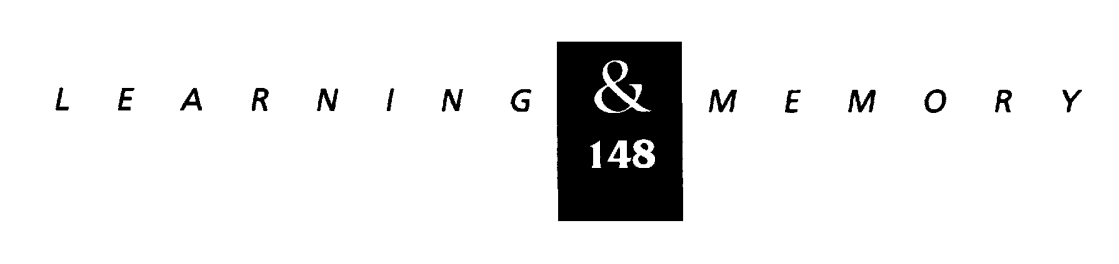


preparations and also blocked the induction of Egr3 mRNA. These data indicate that Egr3 is induced by NMDA-dependent synaptic mechanisms in association with LTP.

Because Egr3 mRNA is expressed at relatively high levels in neocortex of normal, behaving rats, we have examined the hypothesis that basal Egr3 expression is regulated by natural synaptic activity. Blockade of visual activity, by infusing TTX into one eye, results in a rapid reduction of Egr3 mRNA in the deafferented visual cortex. This observation is consistent with the notion that afferent visual activity continuously activates the expression of specific IEG transcription factors in neurons of the visual cortex and thereby regulates their basal expression (Worley et al. 1991; Chaudhuri and Cynader 1993). Visual deprivation in the adult animal results in time-dependent, phenotypic changes in neurons of the visual cortex, including reductions in cytochrome-oxidase and GABA staining as well as increases in type II calcium/calmodulin-dependent kinase (Hendry and Carder 1992). These changes are observed typically several days following continuous visual deafferentation and presumably underlie adaptive cortical plasticity. The rapid time course of changes in Egr3 mRNA with visual deprivation suggests that it may play a regulatory role in long-term changes of neuronal phenotype.

Developmental studies indicate that Egr3 mRNA expression is high in the newborn striatum, septum, piriform cortex, and hippocampus. During the first postnatal week, expression increases markedly in the neocortex. By postnatal day 12 , Egr3 expression is very similar to the adult pattern and level of expression. This developmental and anatomic pattern of expression is similar to that of $z$ if 268 (Worley et al. 1990) with the exception of the high Egr3 mRNA levels in the neonatal striatum. The developmental profile together with observations indicating that physiological activity regulates expression of Egr3 suggest a role for Egr3 in activity-dependent development of brain.

Previous studies have demonstrated that dopaminergic stimulation elicits robust IEG expression in the striatum (Robertson et al. 1989; Graybiel et al. 1990; Cole et al. 1992). Pharmacological agents that modify dopamine-dependent signaling also induce Egr3 in the brain. Cocaine administration results in a rapid increase in Egr3 mRNA in the striatum that is blocked by a selective $\mathrm{D}_{1}$ antagonist. Additionally, haloperidol, a $\mathrm{D}_{2}$ antagonist, induces a rapid increase in Egr3 mRNA in the striatum. This pharmacological profile is similar to that of $c$-fos and zif268, which are also induced in the striatum by $D_{1}$ agonists and $D_{2}$ antagonists (Moratalla et al. 1992; Nguyen et al. 1992; Robertson et al. 1992). A role for cocaineor haloperidol-induced gene expression has been proposed in chronic adaptive responses to these drugs (Hope et al. 1992; Nguyen et al. 1992).

\section{COEXPRESSION OF ZINC FINGER FAMILY TRANSCRIPTION FACTORS IN BRAIN}

Double in situ localizations indicate that Egr3 and zif268 mRNAs are coexpressed in neurons of normal, as well as MECS-stimulated, cortex. zif 268 and $E g r 3$ are also coregulated in granule cells of the hippocampus in the LTP paradigm, in the adult visual cortex in our monocular deafferentation experiments, and in the striatum following cocaine or haloperidol administration. Because zif268 and Egr 3 bind to the same consensus DNA sequence, our observations suggest that interactions between these transcription factors may be important in defining transcription factor-specific effects. The potential complexity of interactions between transcription factors is further underscored by observations that Egr2 and NGFI-C are also induced in brain by seizures (Bhat et al. 1992; Crosby et al. 1992) and that Egr2 is induced with LTP (Worley et al. 1993). A similar situation is evident for the AP1 family of transcription factors, which are coinduced in brain by seizures (Saffen et al. 1988; Sonnenberg et al. 1989). It should be noted that evidence of coexpression of these transcription factors in the brain is largely limited to conditions of nonnatural stimulation such as LTP or seizures, and it remains a possibility that under natural conditions, different transcription factors are expressed in distinct populations of cells. Accordingly, we were interested in demonstrating that Erg 3 and zif 268 are coexpressed in neurons of control cortex.

Several mechanisms have been identified that may be important in determining a specific transcriptional response under conditions in which multiple transcription factors are induced that can bind to the same DNA consensus sequence. Differences in the time course of expression of potentially competing transcription factors may provide for functional distinction. This may be the case for zif268 and Egr3 and for different AP-1 complexes (Sonnenberg et al. 1989). Additionally, transcrip-

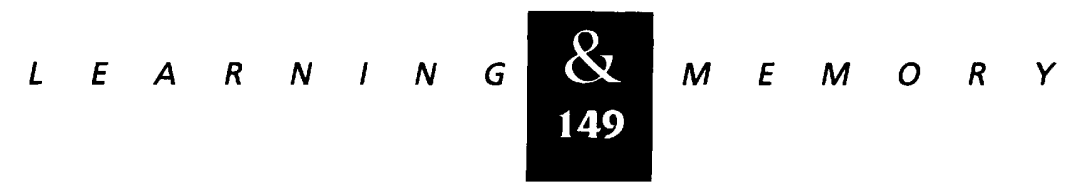


tion factor family members may exhibit differential binding affinities to their shared core consensus sequence or binding may be selectively altered by DNA sequences flanking the core region (Ryseck and Bravo 1991). Transcription factors are also known to interact with other proteins that modulate DNA binding or transcription efficiency (Russo et al. 1993) and undergo post-translation modifications that can alter these functions (Fahrner et al. 1990). zif268 has gained prominence as being one of the most sensitive and specific markers of synaptic activity and plasticity and has focused attention on target genes that may be regulated by zif 268 . Evidence of coexpression of Egr3 and zif268 mRNAs in neurons of control brain suggests that a detailed analysis of mechanisms regulating transcription from their shared core consensus sequence will be important in understanding the molecular basis of natural plasticity.

\section{Acknowledgments}

We are grateful to Daniel Nathans for advice and encouragement in conducting these studies and Ratan Bhat for tissue sections. This work was supported by grants AG09219, EY08900, EY09374, MH00897, HD 01046, a grant from the M.W. Keck Foundation and Krieger Mind/Brain Institute. W.E.K. is a Merck Clinician-Scientist. The publication costs of this article were defrayed in part by payment of page charges. This article must therefore be hereby marked "advertisement" in accordance with 18 USC section 1734 solely to indicate this fact.

\section{References}

Abraham, W.C. and S.E. Mason. 1988. Effects of the NMDA receptor/channel antagonists CPP and MK801 on hippocampal field potentials and long-term potentiation in anesthetized rats. Brain Res. 462: 40-46.

Abraham, W.C., M. Dragunow, and W.P. Tate. 1992. The role of immediate early genes in the stabilization of long-term potentiation. Mol. Neurobiol. 5: 297-314.

Alberini, C.M., M. Ghirardi, R. Metz, and E.R. Kandel. 1994. $C / E B P$ is an immediate-early gene required for the consolidation of long-term facilitation in Aplysia. Cell 76: 1099-1114.

Bailey, C.H., P.G. Montarolo, M. Chen, E.R. Kandel, and S. Schacher. 1992. Inhibitors of protein and RNA synthesis block structural changes that accompany long-term heterosynaptic plasticity in aplysia. Neuron 9: 749-759.

Bhat, R.V., P.F. Worley, A.J. Cole, and J.M. Baraban. 1992. Activation of the zinc finger encoding gene krox-20 in adult rat brain: Comparison with zif268. Mol. Brain Res.

13: $263-266$.
Cao, X.M., R.A. Koski, A. Gashler, M. McKiernan, G.F. Morris, R. Gaffney, R.V. Hay, and V.P. Sukhatme. 1990. Identification and characterization of the Egr-1 gene product, a DNA-binding zinc finger protein induced by differentiation and growth signals. Mol. Cell. Biol. 10: . 1931-1939.

Chaudhuri, A. and M.S. Cynader. 1993. Activity-dependent expression of the transcription factor Zif268 reveals ocular dominance columns in monkey visual cortex. Brain Res. 605: 349-353.

Chavrier, P., M. Zerial, P. Lemaire, J. Almendral, R. Bravo, and $P$. Charnay. 1988. A gene encoding a protein with zinc fingers is activated during $G_{o} / G_{1}$ transition in cultured cells. EMBO f. 7: 29-35.

Chavrier, P., C. Vesque, B. Galliot, M. Vigneron, P. Doll, D. Duboule, and P. Charnay. 1990. The segment specific gene krox 20 encodes a transcription factor with binding sites in the promoter region of the Hox 1.4 gene. EMBO I. 9: 1209-1218.

Christy, B. and D. Nathans. 1989. DNA binding site of the growth factor-inducible protein Zif268. Proc. Natl. Acad. Sci. 86: $8737-8741$.

Christy, B.A., L.F. Lau, and D. Nathans. 1988. A gene activated in mouse $3 \mathrm{~T} 3$ cells by serum growth factors encodes a protein with "zinc finger" sequences. Proc. Natl. Acad. Sci. 85: 7857-7861.

Cole, A.J., D.W. Saffen, J.M. Baraban, and P.F. Worley. 1989. Rapid increase of an immediate early gene mRNA in hippocampal neurons by synaptic NMDA receptor activation. Nature 340: 474-476.

Cole, A.J., S. Abu-Shakra, D.W. Saffen, J.M. Baraban, and P.F. Worley. 1990. Rapid rise in transcription factor messenger RNAs in rat brain after electroshock induced seizures. J. Neurochem. 55: . 1920-1927.

Cole, A.J., R.V. Bhat, C. Patt, P.F. Worley, and J.M. Baraban. 1992. $D_{1}$ dopamine receptor activation of multiple transcription factor genes in rat striatum. J. Neurochem. 58: $1420-1426$.

Crosby, S.D., J.J. Puetz, K.S. Simburger, T.J. Fahrner, and J. Milbrandt. 1991. The early response gene NGFI-C encodes a zinc finger transcriptional activator and is a member of the GCGGGGGCG (GSG) element-binding protein family. Mol. Cell. Biol. 11: 3835-3841.

Crosby, S.D., R.A. Veile, H. Donis-Keller, J.M. Baraban, R.V. Bhat, K.S. Simbruger, and J. Milbrandt. 1992. Neural-specific expression, genomic structure, and chromosomal localization of the gene encoding the zinc-finger transcription factor NGFI-C. Proc. Natl. Acad. Sci. 89: 4739-4743.

Dragunow, M., W.C. Abraham, M. Goulding, S.E. Mason, H.A. Robertson, and R.L. Faull. 1989. Long-term potentiation and the induction of c-fos mRNA and proteins in

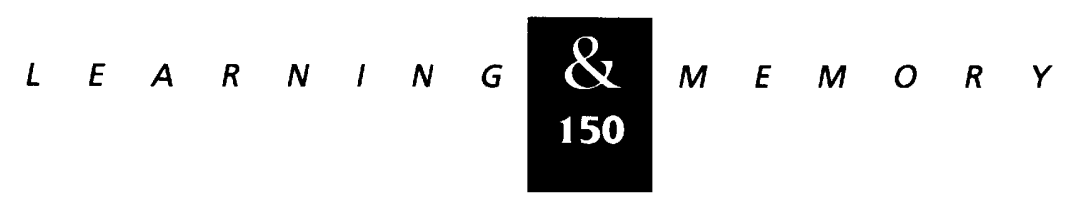


the dentate gyrus of unanesthetized rats. Neurosci. Lett. 101: 274-280.

Fahrner, T.J., S.L. Carroll, and J. Milbrandt. 1990. The NGFI-B protein, an inducible member of the thyroid/steroid receptor family, is rapidly modified posttranslationaly. Mol. Cell. Biol. 10: 6454-6459.

Gashler, A.L., S.A. Swaminathan, and V.P. Sukhatme. 1993. A novel repression module, an extensive activation domain, and a bipartite localization signal defined in the immediate-early transcription factor Egr-1. Mol. Cell. Biol. 13: $4556-4571$.

Graybiel, A.M., R. Moratalla, and H.A. Robertson. 1990. Amphetamine and cocaine induce drug-specific activation of the c-fos gene in striosome-matrix compartments and limbic subdivisions of the striatum. Proc. Natl. Acad. Sci. 87: 6912-6916.

Hendry, S. and R.K. Carder. 1992. Organization and plasticity of GABA neurons and receptors in monkey visual cortex. In Progress in brain research, vol. 90 (ed. R.R. Mize, R.E. Marc, and A.M. Sillito), pp. 477-502. Elsevier, New York.

Hope, B., B. Kosofsky, S.E. Hyman, and E.J. Nestler. 1992. Regulation of immediate early gene expression and AP-1 binding in the rat nucleus accumbens by chronic cocaine. Proc. Natl. Acad. Sci. 89: 5764-5768.

Hyttel, J. 1983. SCH 23390-the first selective dopamine D-1 antagonist. Eur. J. Pharmacol. 91: 153-154.

Jeffrey, K.J., W.C. Abraham, M. Dragunow, and S.E. Mason. 1990. Induction of Fos-like immunoreactivity and the maintenance of long term potentiation in the dentate gyrus of unanesthetized rats. Mol. Brain Res. 8: 267-274.

Jordan, C.A. 1990. In situ hybridization in cells and tissue sections: A study of myelin gene expression during CNS myelination and remyelination. In In situ hybridization histochemistry (ed. M.-F. Chesselet), pp. 39-70. CRC Press, Boca Raton, FL.

Joseph, L.J., M.M. Le Beau, G.A. Jameison Jr., S. Acharya, T.B. Shows, J.D. Rowley, and V.P. Sukhatme. 1988. Molecular cloning, sequencing and mapping of EGR2, a human early growth response gene encoding a protein with zinc binding finger structure. Proc. Natl. Acad. Sci. 85: 7164-7168.

Lanahan, A., J.B. Williams, L.K. Sanders, and D. Nathans. 1992. Growth factor-induced delayed early response genes. Mol. Cell. Biol. 12: 3919-3929.

Lemaire, P., O. Revelant, R. Bravo, and P. Charnay. 1988. Two mouse genes encoding potential transcription factors with identical DNA-binding domains are activated by growth factors in cultured cells. Proc. Natl. Acad. Sci. 85: 4691-4695.

Lemaire, P., C. Vesque, J. Schmitt, H. Stunnenberg, R.
Frank, and P. Charney. 1990. The serum-inducible mouse gene Krox-24 encodes a sequence specific transcriptional activator. Mol. Cell. Biol. 10: 3456-3467.

Lim, R.W., B.C. Varnum, and H.R. Hershman. 1987. Cloning of tetradecanoyl phorbol ester-induced 'primary response' sequences and their expression in density-arrested Swiss 3T3 cells and a TPA non-proliferative variant. Oncogene 1: 263-270.

Linzer, D.L.H. and D. Nathans. 1983. Growth-related changes in specific mRNAs of cultured mouse cells. Proc. Natl. Acad. Sci. 80: 4271-4275.

Mages, H.W., T. Stamminger, O. Rilke, R. Bravo, and R.A. Kroczek. 1993. Expression of PILOT, a putative transcription factor, requires two signals and is cyclosporin A sensitive in T cells. Int. Immunol. 5: 63-70.

McCormack, M.A., K.M. Rosen, L. Villa-Kormaroff, and G.D. Mower. 1992. Changes in immediate early gene expression during postnatal development of cat cortex and cerebellum. Mol. Brain Res. 12: 215-223.

McNaughton, B.L., C.A. Barnes, G. Rao, J. Baldwin, and M. Rasmussen. 1986. Long-term enhancement of hippocampal synaptic transmission and the acquisition of spatial information. J. Neurosci. 6: 563-571.

Mello, C.V., D.S. Vicario, and D.F. Clayton. 1992. Song presentation induces gene expression in the songbird forebrain. Proc. Natl. Acad. Sci. 89: 6818-6822.

Mermod, N., E.A. O'Neill, T.J. Kelly, and R. Tjian. 1989. The proline-rich transcriptional activator of CTF/NF-I is distinct from the replication and DNA binding domain. Cell 58: $741-753$.

Milbrandt, J. 1987. A nerve growth factor-induced gene encodes a possible transcriptional regulatory factor. Science 238: 797-799.

Montarolo, P.G., P. Goetet, V.F. Castellucci, J. Morgan, E.R. Kandel, and S. Schacher. 1986. A critical period for macromolecular synthesis in long-term heterosynaptic facilitation in Aplysia. Science 234: 1249-1254.

Moratalla, R., H.A. Robertson, and A.M. Graybiel. 1992. Dynamic regulation of NGFI-A (zif268, egr1) gene expression in the striatum. J. Neurosci. 12: 2609-2622.

Nathans, D., B.A. Christy, R. Dubois, A. Lanahan, L.K. Sanders, and Y. Nakabeppu. 1991. Transcription factors induced by growth-signaling agents. In Origins of human cancer: A comprehensive review (ed. J. Brugge, T. Curran, E. Harlow, and F. McCormick), pp. 353-364. Cold Spring Harbor Laboratory Press, Cold Spring Harbor, New York.

Nedivi, E., D. Hevroni, D. Naot, D. Israeli, and Y. Citri. 1993. Numerous candidate plasticity-related genes revealed by differential cDNA cloning. Nature 363: 718-722.

Nguyen, T.V., B.E. Kosofksy, R. Birnbaum, B.M. Cohen, and

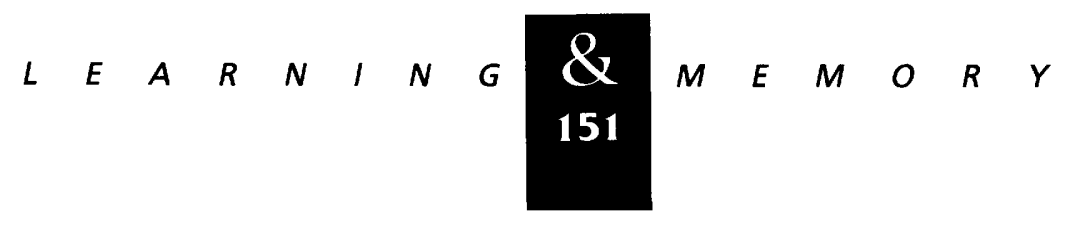


S.E. Hyman. 1992: Differential expression of c-fos and Zif268 in rat striatum after haloperidol, clozapine and amphetamine. Proc. Natl. Acad. Sci. 89: 4270-4274.

Patwardhan, S., A. Gashler, M.G. Siegel, L.C. Chang, L.J. Joseph, T.B. Shows, M.M. Le Beau, and V.P. Sukhatme. 1991. EGR3, a novel member of the Egr family of genes encoding immediate-early transcription factors. Oncogene 6: $917-928$.

Pavletich, N.P. and C.O. Pabo. 1991. Zinc finger-DNA recognition: Crystal structure of a Zif268-DNA complex 2.1 Å. Science 252: 809-817.

Qian, Z., M.E. Gilbert, M.A. Colicos, E.R. Kandel, and D. Kuhl. 1993. Tissue-plasminogen activator is induced as an immediate-early gene during seizure, kindling and long-term potentiation. Nature 361: 453-547.

Rauscher, F.J., J.F. Morris, O.E. Tournay, D.M. Cook, and T. Curran. 1990. Binding of the Wilms' tumor locus zinc finger protein to the EGR-1 consensus sequence. Science 250: 1259-1262.

Reed, G.D. and G.B. Robinson. 1991. Effect of MK801 on long-term potentiation in the hippocampal dentate gyrus of the unanesthetized rabbit. Ann. N.Y. Acad. Sci.

627: $381-384$

Robertson, G.S., S.R. Vincent, and H.C. Fibiger. 1992. D and $D_{2}$ dopamine receptors differentially regulate $c$-fos expression in striatonigral and striatopallidal neurons. Neuroscience 49: 285-296.

Robertson, H.A., M.R. Peterson, K. Murphy, and G.S. Robertson. 1989. $D_{1}$-dopamine receptor agonists selectively activate c-fos independent of rotational behavior. Brain Res. 503: 346-349.

Russo, M.W., C. Matheny, and J. Milbrandt. 1993. Transcriptional activity of the zinc finger protein NGFI-A is influenced by its interaction with a cellular factor. Mol. Cell. Biol. 13: 6858-6865.

Ryseck, R.P. and R. Bravo. 1991. c-Jun, Jun B and Jun D differ in their binding affinities to AP-1 and CRE consensus sequences: Effect of Fos proteins. Oncogene 6: 533-542.

Saffen, D.W., A.J. Cole, P.F. Worley, B.A. Christy, K. Ryder, and J.M. Baraban. 1988. Convulsant-induced increase in transcription factor messenger RNAs in rat brain. Proc. Natl. Acad. Sci. 85: 7795-7799.

Shatz, C.J. 1990. Impulse activity and the patterning of connections during CNS development. Neuron 5: 745-756.

Sheng, M. and M.E. Greenberg. 1990. The regulation and function of c-fos and other immediate early genes in the nervous system. Neuron 4: 477-485.

Sonnenberg, J.L., P.F. McGregor-Leon, T. Curran, and J.I. Morgan. 1989. Dynamic alterations occur in the levels and composition of transcription factor AP-1 complexes after seizure. Neuron 3: 359-365.

Sukhatme, V.P., S. Kartha, F.G. Toback, R. Taub, R.G. Hoover, and C.H. Tsai-Morris. 1987. A novel early growth response gene rapidly induced by fibroblast, epithelial cell and lymphocyte mitogens. Oncogene Res. 1: 343-355.

Sukhatme, V.P., X. Cao, L.C. Chang, C. Tsai-Morris, D. Stamenkovich, P.C. Ferreira, D.R. Cohen, S.A. Edwards, T.B. Shows, T. Curran, M.M. Le Beau, and E.D. Adamson. 1988. A zinc finger-encoding gene is coregulated with c-fos during growth and differentiation, and after cellular depolarization. Cell 53: 37-43.

Worley, P.F., A.J. Cole, T.H. Murphy, B.A. Christy, Y. Nakabeppu, and J.M. Baraban. 1990. Synaptic regulation of immediate-early genes in brain. Cold Spring Harbor Symp. Quant. Biol. 55: 213-223.

Worley, P.F., B.A. Christy, Y. Nakabeppu, R.V. Bhat, A.J. Cole, and J.M. Baraban. 1991. Constitutive expression of zif268 in neocortex is regulated by synaptic activity. Proc. Natl. Acad. Sci. 88: 5106-5110.

Worley, P.F., R.V. Bhat, J.M. Baraban, C.A. Erickson, B.L. MCNaughton, and C.A. Barnes. 1993. Thresholds for synaptic activation of transcription factors in hippocampus: Correlation with long-term enhancement. J. Neurosci. 13: $4776-4786$.

Yamagata, K., K.I. Andreasson, W.E. Kaufmann, C.A. Barnes, and P.F. Worley. 1993. Expression of a mitogen-inducible cyclooxygenase in brain neurons: Regulation by synaptic activity and glucocorticoids. Neuron 11: $371-386$.

Young III, W.S. 1989. Simultaneous use of digoxigenin- and radiolabeled oligodeoxyribonucleotide probes for hybridization histochemistry. Neuropeptides 13: 271-275.

Received April 18, 1994; accepted in revised form July 6, 1994.

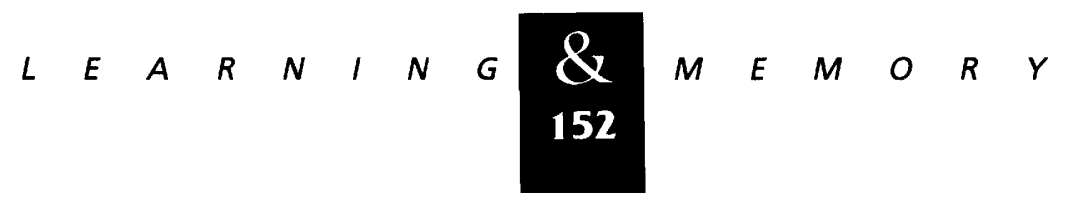




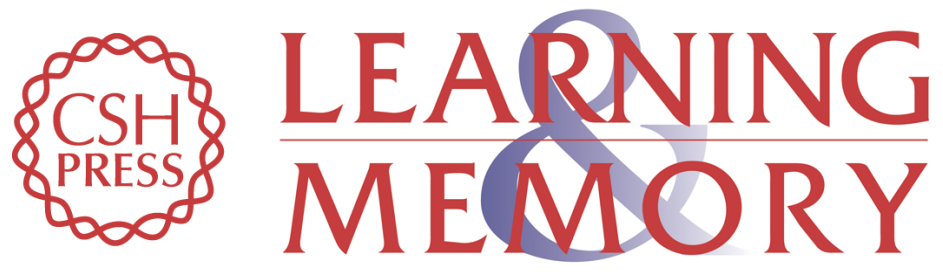

\section{Egr3/Pilot, a zinc finger transcription factor, is rapidly regulated by activity in brain neurons and colocalizes with Egr1/zif268.}

K Yamagata, W E Kaufmann, A Lanahan, et al.

Learn. Mem. 1994, 1:

Access the most recent version at doi:10.1101//m.1.2.140

References This article cites 59 articles, 27 of which can be accessed free at: http://learnmem.cshlp.org/content/1/2/140.full.html\#ref-list-1

License

Email Alerting Receive free email alerts when new articles cite this article - sign up in the box at the Service top right corner of the article or click here. 